\title{
PARTICULARIDADES DEL USO DEL PRETÉRITO IMPERFECTO DE SUBJUNTIVO EN DOS MEDIOS DE COMUNICACIÓN DE CIRCULACIÓN NACIONAL EN ECUADOR: EL COMERCIO Y EL UNIVERSO
}

SPECIFITIES ON THE USE OF SPANISH IMPERFECT SUBJUNETIVE TENSE IN TWO ECUADORIAN NEWSPAPERS DISTRIBUTED NATION-WIDE: EL COMERCIO AND EL UNIVERSO

LAURA ViLLAGÓMEZ ${ }^{1}$

Recibido: 4 de enero de 2017 Aceptado: 6 de marzo de 2017

${ }^{1}$ Pontificia Universidad Católica del Ecuador, Facultad de Comunicación, Lingüística y Literatura, Escuela de Lenguas, Quito, Ecuador (LBVILLAGOMEZ@puce.edu.ec). 



\section{PARTICULARIDADES DEL USO DEL DEL PRETÉRITO IMPERFECTO DE DOS MEDIOS DE COMUNICACIÓN DE CIRCULACIÓN NACIONAL EN ECUADOR: EL COMERCIO Y EL UNIVERSO}

\section{SPECIFITIES ON THE USE OF SPANISH IMPERFECT SUBJUNETIVE TENSE IN TWO ECUADORIAN NEWSPAPERS DISTRIBUTED NATION-WIDE: EL COMERCIO AND EL UNIVERSO}

Laura Villagómez

PALABRAS CLAVE: escritura formal, modo, modalidad, concordancia, imperfecto de subjuntivo, estilo indirecto.

KEYWORDS: formal writing, Spanish subjunctive mood, modal verbs, agreement, Spanish imperfect subjunctive, reported speech.

\section{RESUMEN}

La redacción periodística es un género que experimenta cambios permanentes a todo nivel, desde el del diseño gráfico hasta el de la priorización de temas, pasando claro está, por el lingüístico. En un mundo globalizado, caracterizado por la velocidad de la comunicación y cantidad de información disponible, los medios de comunicación se adaptan a esta dinámica, para interactuar con los usuarios e ir respondiendo a su entorno. En este contexto, la aplica- 
ción de las normas gramaticales a la redacción periodística puede ser un tema de controversia, pero no deja de ser interesante el reflexionar sobre la manera en que se van produciendo estos procesos de cambios lingüísticos en una colectividad que le adjudica un considerable gra- do de importancia a la prensa escrita. El tema puntual de este análisis consiste en identificar las peculiaridades de la utilización del pretérito imperfecto del modo subjuntivo en dos de los medios de circulación nacional del país: El Comercio y El Universo.

\section{ABSTRACT}

Journalism writing is a genre which experiences permanent change at all levels. These innovations range from areas such as graphic design to the prioritization of the topics that will be covered. The linguistic domain in journalism writing is not immune to this transformation. In order to interact with its audiences mass media have effectively adapted to a globalized world characterized by high-speed communications and by the enormous amount of information available to global audiences. In such a context, the need of applying grammar rules to journalism writing may well be considered a controversial topic of discussion. Nonetheless, it is always interesting to reflect about the processes which lead to linguistic change; even more so if these processes occur in the midst of a society which attributes the utmost importance to the written media. This article concentrates on identifying certain peculiarities regarding the use of the Spanish imperfect subjunctive in two journals which are nation-wide commercially distributed in Ecuador: El Comercio and El Universo.

\section{INTRODUCCIÓN}

En Ecuador, la prensa escrita -ya sea en papel o en línea- constituye hoy en día el recurso de lectura al que con mayor asiduidad accede el ciudadano promedio. Los comunicadores o periodistas son profesionales cuyo prin- cipal instrumento de trabajo es la lengua tanto escrita como oral. No solamente la han estudiado, sino que se han familiarizado con ella mucho más que el común de los hablantes o usuarios de la lengua. En este contexto, no deja de ser intere- 
sante que al analizar la gramática en la narración de noticias, artículos de opinión y reportajes, se note una clara influencia de las variantes dialectales ecuatorianas. Frente a este hecho se puede optar por una de estas dos posturas: a) el estilo periodístico debe adaptarse al habla local o b) el estilo periodístico debe inscribirse dentro de ciertos cánones que la convierten en un referente de escritura formal, tomando en cuenta no solamente criterios sintácticos, sino semánticos y pragmáticos.

Uno de los temas gramaticales de la lengua española cuya utilización estándar ofrece mayor dificultad, es el modo subjuntivo especialmente en su forma de pasado o imperfecto; en este artículo se han descrito las peculiaridades del habla quiteña en lo que atañe a la utilización del pretérito imperfecto de subjuntivo, así como las características del habla culta a la que se adscribe la escritura periodística y se han revisado las reglas o normas establecidas en los casos de concordancias temporales con el modo indicativo; en base a ellas se han analizado ejemplos tomados de dos de los diarios impresos de circulación nacional.

El objetivo de este análisis es establecer la manera en que la aplicación de estas reglas influye en la claridad y precisión con que se expresa el mensaje, y evita, por supuesto, malos entendidos y sus consecuencias posteriores, no sin antes recalcar el afán descriptivo y no normativo que ha animado al desarrollo de este trabajo.

\section{ANTECEDENTES}

La utilización del pretérito imperfecto de subjuntivo en el habla ecuatoriana es un tema que no se ha investigado exhaustivamente desde 1982, año en el que Francisco Garcés D., escribió una tesis de licenciatura titulada La substitución del pasado por el presente del subjuntivo en Quito. Su investigación comprendió a grupos tanto de estudiantes cuanto de profesores, la mayoría perteneciente a la clase media de la ciudad. Sus hallazgos revelaron que prácticamente un $80 \%$ de la población encuestada no usaba el pretérito imperfecto de subjuntivo. Al preguntarles la razón de esta práctica, coincidieron en responder que estaban familiarizados con la forma del subjuntivo presente por razones como: "se comprende mejor", "es más exacto", "me gusta", "así hablan en mi casa." Garcés acota al respecto: "Todas estas explicaciones ilustran en principio un convencimiento de que la forma del verbo que seleccionan es definitivamente la adecuada y 
que por lo tanto, es parte intrínseca de su repertorio lingüístico y en segundo lugar [sic] tales afirmaciones demuestran una comprensión del subjuntivo presente." (122) Además sostiene que los estudiantes universitarios evidenciaban una tendencia tres veces más alta que los demás entrevistados, a utilizar el pretérito imperfecto de subjuntivo, lo cual lo llevó a concluir que "la preferencia por el presente de subjuntivo decae a medida que aumenta el nivel educativo."(130)

Posteriormente, en el año 2000, Ana Estrella, en su libro El uso del verbo en el habla de Quito, observa: "el empleo del presente de subjuntivo cuando debería usarse el imperfecto es muy común, tanto en instruidos como no instruidos. Su uso no se limita al habla sino que es frecuente, también, en el lenguaje escrito... en los periódicos no fue difícil encontrar ejemplos de este empleo." (87)

En 2006, Fernando Miño-Garcés incluyó en su libro Gazapos quiteños un capítulo sobre la discordancia entre pasado de indicativo y pasado de subjuntivo: "el problema en el habla quiteña es el uso indebido de la concordancia de tiempos sin poner atención al significado de la frase..." (161). El corpus analizado corresponde a textos escritos por sus estudiantes universitarios de Lingüística en Quito $(151,168)$ y está lleno de inconsistencias de concordancias temporales que afectan no solamente a la lógica sintáctica del discurso, sino también y, sobre todo, al significado: "Para evitar estas ambigüedades, debemos concordar los tiempos de los verbos. Si empezamos narrando en pasado, lo más aconsejable, especialmente para los quiteños que cometemos tantos errores es este campo, es usar todos los verbos en tiempo pasado". (166)

Ya en 1969 Charles Kany había mencionado la utilización del presente de subjuntivo en lugar del imperfecto, "en unas pocas regiones de Hispanoamérica hallamos con frecuencia un presente de subjuntivo usado en oración subordinada en casos en que debería emplearse un imperfecto de subjuntivo de acuerdo con la regla secuencial de tiempos. De acuerdo con dicha regla, se puede emplear un presente de subjuntivo después de un tiempo pasado cuando el sentido de la oración subordinada continúa en el presente: "le dije que lo haga mañana"..."(220) y cita fragmentos de obras literarias ecuatorianas en los que se observa el uso del presente de subjuntivo en todo tipo de oraciones subordinadas. Moreno de Alba en su libro El español de América (2001) observa que se ha realizado muy poca investigación en el campo de la gramática a nivel continental; reconoce que uno de los puntos que por su importancia merecerían estudiarse, es "lo que podría designarse como reducción del paradigma verbal o, si se quiere, 
preferencias americanas por el uso de ciertas formas verbales o tiempos de la conjugación y la poca frecuencia o abandono total de algunos otros." (219). Anota así mismo que en América la forma de imperfecto de subjuntivo terminada en -ra, es la escogida mayoritariamente en todos los dialectos y registros (244). En las pocas ocasiones en que se utiliza en Ecuador el imperfecto de subjuntivo, se emplea la forma en -ra.

La Nueva Gramática de la Lengua Española (NGLE) describe un fenómeno de neutralización de los tiempos, el cual provoca que "una forma asimile a otra u otras y en la práctica se produzca una flexibilización del uso: "El primero es CANTO-CANTARÉ > CANTE y muestra la neutralización de un presente y un futuro. El segundo es HE CANTADO - HABRÉ CANTADO > HAYA CANTADO... La tercera neutralización es CANTÉ-CANTABA-CANTARÍA > CANTARA O CANTASE. Se aplica, por tanto, a dos pretéritos y al condicional... La cuarta y última neutralización es HABÍA CANTADO-HABRÍA CANTADO $>$ [HUBIERA - HUBIESE] CANTADO." (Ibid 1798) Continúa la descripción de esta neutralización: "en algunas variantes del español popular andino se neutralizan la primera y la tercera, por un lado (con tiempos simples), y la segunda y la cuarta por otro (con tiempos compuestos). En estas variantes son comunes secuencias como No llovió. Yo quería que llueva (por...que lloviera)..." (lbid); e incluso, como lo observa Moreno de Alba, en cláusulas condicionales puede, en muchas regiones de América Latina, aparecer el pospretérito (cantaría) en lugar del imperfecto de subjuntivo (cantara) en la apódosis de una oración condicional: "si tendría tiempo, iría". (246).

Tres de las investigaciones que se han mencionado, las de Garcés, Estrella y Miño se han realizado entre personas con educación formal en la lengua. Es justamente este factor el que nos ha llevado a cuestionarnos sobre los motivos por los cuales las personas que han sido expuestas a un estudio sistemático y formal de la lengua, terminan apartándose del canon y luego hablan -pero sobre todo escriben- sin mayor observancia de las reglas relativas a la concordancia modal y temporal.

Al abrir un ejemplar de cualquiera de los diarios de mayor circulación en el país, es posible cerciorarse que no existe un criterio estable ni definido para utilizar el pretérito imperfecto de subjuntivo, pues si bien en algunos casos se observan las reglas tanto sintácticas como semánticas y pragmáticas, en otros hay una tendencia a seguir la variante dialectal propia del español quiteño e incluso andino. Se podría argumentar que modernamente, y de acuerdo con el pensamiento de Domingo Sarmiento, existe un consenso entre lingüistas y académi- 
cos que defiende la validez del uso de las variantes dialectales, en consideración al número de hablantes y a la permanencia en el tiempo, y que la escritura periodística se adhiere a esos usos locales, por cuestiones de identidad y pertenencia. Sin embargo, esta escritura se inscribe dentro del ámbito del habla culta cuyas características se revisarán a continuación.

\section{LA REDACCIÓN PERIODÍSTICA Y EL HABLA CULTA}

Tradicionalmente el género periodístico se había identificado con el quehacer literario, de manera que solamente en la segunda mitad del siglo XX, con el advenimiento de las agencias de prensa, comenzó a valorarse como un género independiente, por las características propias del artículo periodístico, "-concisión, objetividad, veracidad, etc.- muy diferentes a las de los textos de literatura;" (Mancera Rueda 2009). Este origen literario del género -o estilo periodístico, como lo llamarían otros-, lo inscribe dentro del ámbito de la lengua culta, lo cual le confiere dos propiedades estructurales según los postulados de los lingüistas de la Escuela de Praga: intelectualización y estabilidad flexible.

Al campo de la intelectualización pertenecen el léxico, la gramática, la ortografía, es decir las características de la lengua que la convierten en un vehículo de comunicación estandarizado para efectos del intercambio formal de información y que le permiten exhibir el rigor necesario al momento de producir enunciados precisos, comprensibles y coherentes: "En el plano sintáctico, este rigor "se manifiesta particularmente en la estructura oracional por la preferencia que manifiesta la lengua culta por oraciones normalizadas de dos constituyentes, el sujeto y el predicado, claramente diferenciados formalmente." Havranek (ctd en Torrejón 5), quien añade: "La intelectualización se manifiesta a nivel textual en una rigurosa y elaborada técnica de superordinación y subordinación en oraciones." (Ibid.) Condiciones estas, insoslayables para producir mensajes objetivos y evitar ambigüedades que pudieran restar credibilidad a la fuente.

A esta propiedad estructural de intelectualización se suma otra muy importante, la de estabilidad flexible, aquella que reconoce "la capacidad intrínseca que presentan las lenguas cultas para cambiar, adaptándose a las múltiples y variadas necesidades de la vida cultural moderna, y al mismo tiempo exhibir un grado tal de estabilidad que les permite seguir siendo ellas mis- 
mas a pesar de los cambios." (Torrejón 6) La flexibilidad convierte a la lengua en un mecanismo eficiente y vigente de expresión, mientras que la estabilidad, asentada en una codificación, la transforma en un "marco de referencia firme frente a la variabilidad dialectal y variabilidad individual del habla popular." Garvin (ctd en Torrejón 7) Esta habla culta se convierte entonces, en un modelo a imitar, entendiéndose que este será lo suficientemente permeable a los cambios que experimenta la lengua en un mundo globalizado y en constante evolución de ideas, estilos, tendencias y medios de comunicación.

Aparte de estas dos cualidades estructurales, la lengua culta posee dos propiedades culturales que se originan en los efectos que tiene sobre ella el contexto social. "... dentro de este conjunto se distinguen por lo menos dos particularidades: arraigo y urbanización." Gallardo (ctd en Torrejón 15). La característica cultural de arraigo implica que la lengua es considerada por una comunidad, una parte de su historia y de su identidad, que los cohesiona y los diferencia de los demás. Según Torrejón esta propiedad de arraigo de una lengua:

...es una de las condiciones más importantes para que se pueda lograr la estandarización de ella. Evidentemente, la lengua tiene que estar arraiga- da... para que la comunidad decida entregarse a la tarea de cultivarla;... los hispanoamericanos por una parte, enfrentados a otras reglas cultas, nos adherimos a una norma panhispánica que simboliza todo lo que nos une frente a estas, y por otra parte, cuando nos enfrentamos a otras variedades del español nos sentimos fuertemente ligados a nuestras variedades nacionales o locales. (110-11).

La otra propiedad cultural de la lengua es la urbanización: "... decir que un idioma está urbanizado significa que la comunidad hablante ha desarrollado ciertas formas de erudición lingüística..."Gallardo (ctd en Torrejón 11); según el autor, esta habla culta se considera "un bien público" porque es "accesible a todos los miembros de la comunidad." (Ibid). El autor aclara que "accesibilidad" no es lo mismo que "disponibilidad", pues tener acceso a un lengua culta depende de varios aspectos sociales, económicos y políticos, que son los que en realidad determinan el acceso que la población tiene a ciertos "bienes públicos". Como habíamos mencionado inicialmente, las investigaciones tomadas en cuenta para este trabajo, se han hecho en una población de lengua urbanizada y arraigada.

Los medios de comunicación son, probablemente, una de las maneras más comunes en que la lengua se 
pone a disposición de la comunidad y es el habla escrita la que de forma más evidente puede exponer y reforzar las propiedades que se han mencionado: intelectualización, estabilidad flexible, arraigo y urbanización.

\section{TEORÍA GRAMATICAL: CONCORDANCIA DE MODOS Y TIEMPOS VERBALES}

Sin ignorar la evolución natural que experimentan las lenguas tanto por el proceso de contacto con otras, cuanto por la convivencia con diferentes variantes regionales y por lo que se llamaría la simplificación de las formas verbales, la lengua culta que hemos analizado en la sección anterior, se cimienta en un canon que busca su estandarización o formalización, al pasar del ámbito personal y familiar a uno colectivo con función social. Una vez que el habla se convierte en un instrumento de comunicación masivo, pasa a formar parte del repertorio de habla culta que los lectores esperan encontrar en un medio de comunicación que goza de cierto prestigio. Por esta razón, en la presente sección se hará un resumen de los criterios gramaticales que rigen la utilización de los modos, en particular en oraciones subordinadas, con énfasis en la concordancia de tiempos entre indicativo y subjuntivo, pero antes se realizará una breve revisión de dos conceptos fundamentales: modo y modalidad.

De acuerdo con la NGLE, Nueva gramática de la lengua española de la
Real Academia de la Lengua, el modo expresa la modalidad, es decir:

...la manifestación lingüística de la actitud del hablante en relación con el contenido de los mensajes. El concepto de modalidad entronca con el tradicional animus loquendi; uno y otro concepto expresan la idea que las informaciones lingüísticas se interpretan en múltiples casos como acciones verbales que se atribuyen al que las emite, y también como expresiones de sus puntos de vista o de sus reacciones afectivas hacia los contenidos del mensaje. (3112)

En otras palabras, el modo verbal tiene la función de personalizar los enunciados de acuerdo con el punto de vista y a la intencionalidad del hablante. El modo indicativo tiene la función de describir, narrar hechos y circunstancias, desde una perspectiva declarativa, objetiva, apegada a la realidad, (DICTUM), mientras que el subjuntivo tiene la propiedad de permitir que el hablante se 
distancie de lo fáctico para expresar una postura personal, muchas veces subjetiva (MODUS).

El verbo en español está sujeto a nociones de "tiempo", "aspecto", "modo" "número" y "persona". El tiempo verbal - lo que Alarcos Llorach (1994) Ilama "perspectiva temporal" informa "acerca de la localización de lo que se describe en relación con el momento del habla de la enunciación o con otro punto de referencia..." (NGLE 1865); de ahí que la selección del tiempo de la oración subordinada, cumpla el papel de precisar o clarificar el momento en que sucedieron o sucederán los hechos, en relación con el momento en que ocurre el enunciado de la oración principal. Probablemente por esta razón, en el estilo periodístico se echa mano al recurso de flexibilización de la lengua, y se producen combinaciones como: pretérito perfecto simple o pretérito imperfecto de indicativo en la cláusula principal con presente de subjuntivo en la subordinada: "El Presidente pidió a su gabinete que renuncie en diciembre", -porque la acción aún no ha ocurrido -quizás ocurra en el futuro-, sin advertir que la frase: "El Presidente pidió a su gabinete que renunciara en diciembre" también implica que la acción todavía no se ha llevado a cabo, pues el subjuntivo "es, en efecto, el tiempo [sic] que crea en el habla y la escritura la escena cóncava de la suposición." (Verdú
1999). Se hizo un pedido y el que se haya cumplido o no, lo explicará el contexto. Al parecer, esta combinación de tiempos es frecuente también en la redacción periodística de otros países:

This is common, especially in newspapers, when the main clause refers to the past and mentions an action that has still not taken place in the reader's or hearer's present: el secretario de las Naciones Unidas pidió ayer a Estados Unidos que no actúe unilateralmente contra Irak (El País, Sp.).... it is also common in popular Latin-American speech where standard language requires the past Subjunctive." (Butt \& Benjamin 284)

La concordancia entre los tiempos del subjuntivo y los del indicativo, sin embargo, no puede analizarse aisladamente, sino como parte de la cadena de concordancia que se aplica en cualquier discurso indirecto: "El estilo indirecto bastante frecuente en la narración periodística, determina la concordancia de modos y tiempos y le da una lógica al discurso, además de aportarle claridad. Así pues, si se va a citar indirectamente una declaración o un enunciado, se deberá decidir si el verbo introductorio va en presente o en pretérito." (Fernández 53). Al analizar casos de discordancia entre las formas de pasado de indicativo e imperfecto de subjuntivo, encontramos que frecuentemente, esta solo es una parte de 
un texto escrito en estilo indirecto: "El futbolista afirmó que volverá a trabajar, tan pronto como se recupere de la lesión en la rodilla." Esta declaración del futbolista se ubica en el tiempo pasado, "afirmó"; de acuerdo con la concordancia de modos y tiempos, si transmitimos un mensaje de manera indirecta con un verbo de comunicación como "afirmar" en pretérito perfecto simple, el verbo de la oración subordinada sustantiva se formaliza en condicional y la cláusula adverbial, en imperfecto de subjuntivo. Así pues, tenemos: "El futbolista afirmó que volvería a trabajar, tan pronto como se recuperara de la lesión en la rodilla." Obsérvese este otro caso: "Pero Rodríguez ... explicó que fue la cercanía de Chumpi con el prefecto azuayo Paúl Carrasco la que sirvió para que el shuar se convirtiera en la cuarta autoridad local dentro del colectivo político, para las elecciones del 2017." El Comercio. 25 jul. 2016. 1:3 Impreso. En esta cita, se empieza a transmitir el mensaje con un verbo en pretérito: "explicó", lo cual ubica la información subsiguiente en un contexto en el pasado que afecta a todas las acciones: "fue, sirvió, se convirtiera." Esta información se refiere a una acción ya concluida en el pasado, pero si la acción de "convertirse" estuviera aún por suceder, se podría utilizar, igualmente, el imperfecto de subjuntivo: "el tiempo es un categoría DEÍCTICA, por tanto, REFERENCIAL...las informaciones temporales permiten localizar -directa o indirectamente- los acontecimientos en relación con el momento en que se habla." (NGLE 1673-4), aunque también se pueden ubicar en un punto temporal identificado desde el momento del habla: "la sintaxis de la concordancia de tiempos es una consecuencia de esta doble propiedad, que también se pone de manifiesto en el discurso indirecto." (NGLE:3284)

Al respecto, Rojo y Veiga en la Gramática descriptiva de la lengua española (GDLE) son categóricos en afirmar que "la reducción en el número de distinciones temporales operada en el subjuntivo no afecta al funcionamiento de las que conservan su funcionalidad, que actúan con igual firmeza que el indicativo" y difieren ampliamente de las posturas teóricas que han adjudicado a los tiempos del subjuntivo únicamente un valor "relativo" frente a un verbo regente, y sostienen que estas formas poseen "valores temporales propios" (44.3.2.)

Los tiempos verbales se clasifican tradicionalmente según los tres criterios siguientes:

1. Su estructura morfológica.

2. Su anclaje temporal: anterioridad, simultaneidad y posterioridad.

3. Sus características aspectuales. (NGLE 1675) 
El segundo criterio es probablemente, el que mayores dificultades presenta aun al hablante nativo instruido formalmente en la gramática, porque en la realidad, la acción de la oración subordinada puede ocurrir de manera anterior, simultánea o posterior al momento en que se habla, de manera que el anclaje temporal puede volverse ambiguo: "Comprender correctamente la cronología relativa y la correlación temporal exige tener en cuenta que las mismas relaciones temporales entre los acontecimientos pueden ser enfocadas de modos diversos y, en consecuencia, expresadas de distintas maneras. De una parte, la orientación con respecto a la forma verbal de la cláusula dominante no es la única posibilidad existente. Lo que se presenta habitualmente en las gramáticas como ruptura de la correlación temporal es el resultado de la prioridad concedida en ciertos casos a la orientación con respecto al origen, que no es contradictoria con la otra." (Fernández López 4). Carrasco Gutiérrez en la GDLE, se refiere a los casos no canónicos de concordancia de tiempos y entre ellos incluye algunos en los que se admite el uso del presente de subjuntivo en lugar del imperfecto "cuando la oración sustantiva expresa una verdad de duración indefinida o eterna o se refiere a un acontecimiento que el hablante considera relevante, verdadero o aún válido en el momento del habla." (47.2.3.1) Nótese que en estos casos, llamados por el autor "interpretaciones de doble acceso" solamente se incluyen oraciones subordinadas sustantivas y aclara que estas "son posibles bajo condiciones muy estrictas", pues si la acción de la subordinada acontece al mismo tiempo que la del enunciado principal, no puede formalizarse con un presente sino solamente con el imperfecto de subjuntivo. Obsérvese la diferencia entre:

a. Le pedí que me tenga listo el material para el próximo sábado.

b. Le pidió que tuviera listo el material ayer mismo.

En b. el presente no es admisible porque la acción de la subordinada ocurre simultáneamente al tiempo del habla y los dos tienen lugar en el pasado.

La NGLE (1797) presenta un cuadro que ejemplifica la concordancia de tiempos de los dos modos. Con fines didácticos hemos elaborado un cuadro basado en este, que incluye también, las concordancias del subjuntivo con el condicional. (Ver Anexo 1)

Por su parte, la Gramática descriptiva de la lengua española, al referirse a los usos rectos de las formas verbales indicativas sostiene que "es fácil establecer las correspondencias temporales" de estas con los usos rectos de las subjuntivas, y presenta un cuadro que grafica 
la correspondencia de los tiempos entre los dos modos. (Ver Anexo II)

Como se puede ver en los dos cuadros presentados, tanto a nivel prescriptivo (NGLE) como descriptivo (GDLE), el pretérito imperfecto de subjuntivo se relaciona con tres tiempos del indicativo: co-pretérito o pretérito imperfecto, pospretérito o condicional y pretérito simple perfecto o indefinido. En ningún caso se observa la relación de estos tiempos del indicativo con el presente de subjuntivo, aunque como se ha mencionado anteriormente, esta relación puede darse en caso que la acción de la subordinada esté por suceder en el futuro o no se haya delimitado en el tiempo.

La utilización del pretérito imperfecto de subjuntivo en cláusulas adverbiales de temporalidad, tales como: después de que, luego de que, o en cláusulas adverbiales de indeterminación: donde, en el lugar, etc., se presenta tanto en concordancia con el condicional, para expresar acciones que no han sucedido todavía: "el juez dijo que emitiría un veredicto después de que se presentaran todas las pruebas" o "aseguraron que tomarían medidas emergentes en los lugares donde hubiera mayor grado de contaminación", y en cláusulas subordinadas adverbiales de temporalidad utilizadas para informar del tiempo o momento en que se realizaría la acción enunciada en la principal: "fue necesario que enviaran ayuda humanitaria, tan pronto como las condiciones climatológicas lo permitieran" o "le pidieron que regresara a su oficina después de que todo se hubiera aclarado". Las razones de esta concordancia son dos:

a) de carácter sintáctico: según la NGLE, el criterio sintáctico que prevalece actualmente en relación con esta materia es el denominado "esfera temporal" (1684); el tiempo del verbo perteneciente a la oración principal (V1), determina el tiempo de la subordinada (V2), en razón a la relación de dependencia que existe entre estas; así, si el verbo de la oración principal está en tiempo presente o futuro de indicativo, el de la subordinada estará en presente de subjuntivo, mientras que si lo está en pretérito, cualquiera sea el aspecto, o en pospretérito, el de la subordinada estará en pretérito imperfecto de subjuntivo.

b) de carácter semántico: el indicativo es el modo de la declaración, de la aserción, mientras que el subjuntivo es el modo de la no-declaración, de la falta de aserción. Si se habla de una acción que todavía no ha ocurrido, como en el caso de las cláusulas temporales revisadas, o si se expresa un juicio valorativo o una intención, el subjuntivo es el modo a emplearse.

Por lo tanto, en aquellos casos en que se relatan hechos realmente acontecidos en el pasado, se utiliza el indicativo: "el juez dijo que emitió un veredicto 
después de que se presentaron todas las pruebas" o "aseguraron que tomaron medidas emergentes en los lugares donde hubo mayor grado de contaminación", porque este es el modo de la declaración, de la certeza.

A pesar que el pretérito imperfecto (CANTARA O CANTASE) -a decir de los autores de la NGLE: "es el tiempo más complejo del modo subjuntivo, tanto por los contextos sintácticos en los que se usa como por la variedad de los significados que expresa", existe una cierta predilección por utilizarlo en contextos que requieren la presencia de un pretérito perfecto simple o de un pluscuamperfecto de indicativo. Quizá la explicación esté en la etimología del imperfecto de subjuntivo, tal como lo registra la NGLE: "la variante en -ra del imperfecto procede del pluscuamper- fecto de indicativo latino (amaveram "había amado"), mientras que la variante en -se procede del pluscuamperfecto de subjuntivo (amavissem "hubiera amado")..." (NGLE 1803). Al respecto la GDLE sostiene que "desde el punto de vista modal nos hallamos, ciertamente, ante un empleo indicativo aunque algunos autores hayan querido ver en él un valor modal subjuntivo." (44.5.3). Curiosamente, esta sustitución muy en boga en el medievo constituye hoy en día uno de los usos más frecuentes en la prensa escrita: "Un guía penitenciario es investigado luego que un privado de la libertad del Centro de Rehabilitación Social del cantón Ambato, en Tungurahua, escapara." El Comercio. 22 jul. 2016. 1:6. Impreso. Aunque la acción de "escapar" efectivamente se lleva a cabo y es la que desencadena la investigación.

\section{ANÁLISIS DE CASOS}

Una vez revisada la teoría tanto estilística como lingüística que, idealmente, debería regir a la escritura periodística, se han analizado algunos ejemplos tomados de dos medios de comunicación impresos, de circulación nacional, y se los ha clasificado en cua- tro grupos, de acuerdo con criterios sintácticos, semánticos, dialectales y pragmáticos. Entre estos grupos se incluye el correspondiente a los casos en que se observa la aplicación de las reglas de concordancias de tiempos, tal como se lo prescribe la gramática estándar. 


\section{Grupo 1.}

Concordancia del pretérito y del pospretérito de indicativo con el imperfecto del subjuntivo.

En estas oraciones se observa la regla de concordancia temporal entre la oración principal o subordinante y la cláusula subordinada. Los ejemplos incluyen cláusulas adverbiales temporales, cláusulas sustantivas de influencia y finalidad y cláusulas hipotéticas.

a. "Antes de que este plan fuera implementado, en Quito pasaba lo mismo que en otras ciudades del país..." El Comercio. 2 jul. 2016.1: 2. Impreso.

b. "Es decir, que con el programa el año pasado se evitó que nacieran cerca de unos 35000 animales." Ibid

c. "Triste sería que, en medio de las inmensas posibilidades de vivir mejor, de forma humana, participativa, dialogal y corresponsable, nos fuéramos convirtiendo en consumidores ilimitados al servicio de nuestra codicia." Ibid: 3 jul.2016. 1:4. Impreso.

d. "Impulsó varias alternativas y diálogos que finalmente se concretaron el 9 de junio en el que las partes acordaron que se reuniera el Consejo Superior integrado por sus miembros no cuestionados para proceder a la con- vocatoria a la consulta y a la elección de rector hasta el 29 de julio. "Lamentablemente, el día 27 de junio el entonces presidente del Parlamento Andino no respetó el acuerdo e impidió que el proceso de consulta y designación se realizara; todo esto ante la pasividad de las autoridades del Consejo de Educación Superior (CES), conocedoras de los términos de dicho acuerdo". Ibid: 1 ago. 2016. 1:5. Impreso.

e. "Fue Rodríguez el que convenció al director del diario El Telégrafo, José Abel Castillo, para que se publicara, una vez a la semana, una página deportiva." El Universo 8 ene. 2017. 4:3

f. "Fue un lujo para el periodismo deportivo nacional que se incorporaran a esa actividad los hermanos Manuel Eduardo y Abel Romero Castillo." Ibid

g. "El voto facultativo, para todos, pudo haber sido una idea exitosa y no la mera obligación de la captación de votos, si es que realmente hubiera la iniciativa de instruir y practicar la formación de una identidad patriota real y no demagoga." Ibid 1:9 


\section{Grupo 2:}

Doble acceso

Como se había mencionado anteriormente, tanto en la GDLE como en la NGLE, se hace referencia a los casos no canónicos de concordancia, es decir, aquellos que admiten el empleo del verbo subordinado en presente de subjuntivo, aunque el subordinante esté en pretérito, sea porque la oración sustantiva se refiere a una acción a realizarse en el futuro o a una que se mantiene vigente y relevante al momento de la enunciación.

a. "Los niveles de competitividad entre ambos países son dispares", dijo y, por ello, solicitó que se excluya al sector automotor" El Comercio 22 ago. 2016. 1:4. Impreso.

En esta noticia se hace alusión a una reunión ya ocurrida, en la que se negociaron ciertas condiciones, para futuros acuerdos. Por esta razón se utiliza en la subordinada un presente de subjuntivo. El imperfecto cumpliría la misma función de referirse a un tema que aún no se ha llevado a cabo y que quizás nunca llegara a realizarse: "solicitó que se excluyera al sector automotor."
b. "El Canciller Guillaume Long insistió en que la Unión Europea suprima la solicitud de visado para las estancias

de corta duración a los ecuatorianos." Ibid 12 jul. 2016 1:8 Impreso.

La cláusula principal se refiere a una acción en el pasado, sobre un hecho que aún no ha ocurrido -por eso, quizás, el articulista opta por el presente de subjuntivo. Nótese que se podría decir: "insistió..........suprimiera", pues el imperfecto de subjuntivo puede referirse a una acción coexistente o posterior a la de la cláusula principal.

c. "Aunque hubo reportes que indicaban que el atacante gritó en algún momento deltiroteo "Yo soy alemán", la policía aseguró que no habían podido confirmar ni desestimar esa información y pidieron a los ciudadanos que les remitan los videos de lo ocurrido para analizarlos." Ibid 22 jun. 2016 1:7. Impreso.

La narración de los hechos se hace toda en pretérito, pero al momento de introducir una cláusula de intención o propósito en subjuntivo, se cambia al presente, quizás porque pragmáticamente, la acción de "remitir" se ubica en el futuro

d. Con globos y banderas de la Unión Europea (UE), decenas de miles de personas se manifestaron ayer en Londres en contra del Brexit"y para pedir 
que el gobierno no invoque el decisivo artículo 50, que iniciará el proceso de ruptura del Reino Unido con Bruselas." Ibid 3 jul. 2016. 1:9. Impreso.

Este párrafo se contextualiza explícitamente en el pasado, con el adverbio de tiempo "ayer", pues narra un evento ya ocurrido que busca influenciar en una acción a futuro; por esta razón el autor continúa con un presente de subjuntivo y termina con un futuro de indicativo.

e. "A cuatro meses de que se dé el cambio de mando presidencial, el presidente Rafael Correa concretó ayer el quinto cambio de ministros en su gabinete." El Universo 7 ene.2017. 1:3

La acción de cambio presidencial no ha ocurrido todavía en el momento del cambio de ministros, $y$ tal vez por ese motivo el reportero utiliza en la cláusula temporal subordinada, el presente de subjuntivo, en lugar del imperfecto, que es el que concuerda gramaticalmente con la oración subordinante.

f. "Marisol Peñafiel (AP), integrante de la mesa, señaló que está prevista una nueva comparecencia del fiscal la próxima semana para que se complete su exposición sobre este tema,..." EI Universo 7 ene.2017. 1:4
En este párrafo escrito en estilo indirecto y contextualizado en el pasado, se utiliza el presente de indicativo en las dos cláusulas subordinadas, probablemente porque el hecho del que se habla, ocurrirá en un tiempo futuro. Si el autor hubiera seguido la cadena de concordancia: "señaló que estaba prevista la comparecencia del fiscal la próxima semana para que se completara su exposición..." el sentido de la frase sería exactamente el mismo.

9. "Pero todo se derrumbó el pasado jueves, cuando Ilamó al Congreso a elaborar un programa de asistencia médica alternativo que reduzca los costos y mejore la atención según Reuters." El Universo 8 ene.2017. 1:11

El hecho relatado en este párrafo ocurrió en tiempo pasado "el pasado jueves", sin embargo en la cláusula subordinada de indefinido, se opta por el presente de subjuntivo para las dos acciones, quizás porque "el programa de asistencia médica alternativo" que se busca, deberá entrar en vigencia en el futuro.

h. "En semanas anteriores, el Cuerpo de Bomberos recomendó que no se quemen los años viejos gigantes para evitar, entre otras razones, el riesgo que podrían tener casas aledañas por la 
quema y el uso de explosivos como camaretas." El Universo 8 ene.2017. 1:14

Aunque la recomendación se realizó en el pasado, por el contexto de la noticia, su efecto puede extenderse a un tiempo indefinido, tanto en el presente como en el futuro.

\section{Grupo 3:}

$\underline{\text { Subjuntivo con valor de indicativo }}$

Como se ha mencionado en la sección anterior, el estilo periodístico ha desarrollado una tendencia a utilizar el imperfecto de subjuntivo, en remplazo del pretérito de indicativo para narrar hechos acaecidos en la realidad, es decir acontecimientos que no admiten un matiz de falta de certeza o de subjetividad. Este fenómeno confiere al subjuntivo un valor de indicativo y de acuerdo con los casos encontrados en este análisis, el uso más frecuente se encuentra en cláusulas adverbiales de temporalidad, específicamente en aquellas introducidas con los adverbios de posterioridad: después de que yluego de que.

\section{a. "El cuerpo legislativo aceptó a} trámite el pedido de juicio político en su contra, luego de que se conociera que el Ministerio de Educación no contrató pólizas de seguro para la infraestructura educativa, específicamente tras los daños que sufrió Ia Unidad Educativa del Milenio de Pedernales, en el terremoto del último 16 de abril." El Comercio 25 jul. 2016. 1:3. Impreso

Este es un ejemplo del uso del imperfecto de subjuntivo en lugar del pluscuamperfecto de indicativo. Primero "se conoció que el Ministerio no había contratado pólizas, y luego el cuerpo legislativo aceptó a trámite el pedido de juicio...". Se presenta aquí una secuencia de acciones efectivamente ocurridas en el pasado.

b. "(Anastasio Somoza)...reconoció el vil asesinato del periodista estadounidense, Bill Stewart, (ABC News) cometido en esos días a cargo de la Guardia Nacional y que fue el detonante para su salida en poco tiempo y posterior huida a Paraguay, donde fuera asesinado." El Comercio 22 ago. 2016. 1:11. Impreso.

En este párrafo se relata una serie de acontecimientos que originan el asesinato de Somoza. Este es un hecho histórico que efectivamente ocurrió, por lo cual se debería utilizar el pretérito de indicativo para narrarlo: "fue el detonante para sus salida en poco tiempo y posterior huida a Paraguay, donde fue asesinado." 
c. "Temer consumó su venganza política sobre la que fuera su aliada en una extraña alianza de Gobierno durante cinco años y medio." El Comercio 4 sep. 2016. 1:10. Impreso.

La cláusula subordinada de relativo se refiere a alguien que realmente fue aliada de Temer, de manera que el imperfecto de subjuntivo cobra aquí un valor de indicativo: "Temer consumó su venganza política sobre quien fue su aliada..."

d. "Descansó en la paz del Señor la que en vida fuera, Sra........." El Comercio 7 sep. 2016 2:5. Impreso.

Este es un uso del imperfecto de subjuntivo que se encuentra con mucha frecuencia en los partes mortuorios. No deja de ser interesante que se utilice el modo de la irrealidad, en un discurso que tiene un valor testimonial: aquella persona ciertamente vivió.

\section{e. "Al menos 33 presos fueron brutal-} mente asesinados en la madrugada de ayer en una cárcel de Roraima, en el norte de Brasil, cuatro días después de que una sangrienta venganza dejara 56 muertos en un presidio de Manaos, en plena guerra entre bandas por el control del narcotráfico en esa zona." El Universo 7 ene.2017. 1:4
En este párrafo se da cuenta de un hecho ciertamente acaecido en el pasado, por lo tanto, en la cláusula adverbial temporal, se debería utilizar simplemente el pretérito indefinido de indicativo para reportar que la venganza "dejó 56 muertos".

f. "Cinco sucumbieron a sus heridas y trágicamente murieron", dijo ayer el alguacil del condado de Broward (al que pertenece Fort Lauderdale), Scott Israel, en conferencia de prensa en el terminal, luego de que se controlara la situación." Ibid.

La utilización del imperfecto de subjuntivo en la cláusula temporal crea cierta ambigüedad, la misma que se podría evitar utilizando en pretérito indefinido de indicativo, pues la situación realmente se "controló".

\section{Grupo 4:}

Oraciones en las que no se observan las reglas de concordancia entre modos $y$ tiempos.

a. "Se ha dicho que Churchill fue un gran erizo, ya que pudo transmitir a su pueblo la fuerza moral necesaria para que continúe batallando contra el nazismo, aun cuando la victoria parecía lejana y, en ciertos momentos, hasta improbable." El Comercio 21 jul. 2016. 1:9. Impreso. 
Este párrafo se refiere a un hecho histórico ocurrido completamente en el pasado y como tal, todos los verbos utilizados se formalizan en pretérito de indicativo, pero al introducir una cláusula de finalidad, se opta por el presente de subjuntivo, que afecta a la sintaxis de la oración y le resta claridad al sentido. Con el imperfecto de subjuntivo se tendría: "pudo transmitir a su pueblo la fuerza moral necesaria para que continuara batallando...", con lo cual se obtiene una mejor contextualización de los hechos acaecidos en un momento determinado.

b. "De acuerdo a las estadísticas de Consejo de la Judicatura, entre enero y junio de este año unos 171 extranjeros fueron convocados a audiencias en las unidades judiciales de Tulcán, capital del Carchi, a fin de que expliquen su permanencia jurídica en el país." Ibid 3 ago. 2016 1:6. Impreso.

El hecho referido está contextualizado en el pasado, por lo cual la acción de "explicar" de la cláusula adverbial de finalidad, efectivamente llevada a cabo también en el pasado, debería concordar con el tiempo del verbo de la oración principal: "fueron convocados....a fin de que explicaran...."

c. "En la tarde confirmó que los soldados y policías se quedarán el tiempo que sea necesario para detener a los responsables de la muerte del policía José Luis Mejía." El Comercio 17 dic. 2016 2:1. Impreso

Este tipo de discordancia se produce con frecuencia en oraciones de estilo indirecto que empiezan en pretérito y continúan en futuro para luego complementarse con una subordinada en presente de subjuntivo. Lo correcto es: confirmó .se quedarían...........que fuera.

d. "Temprano, Navas confirmó a EL COMERCIO que, entre policías y militares, a la zona fueron desplegados 1000 hombres de diferentes cuarteles. Y descartó que el despliegue sea excesivo." El Comercio 17dic. 2016 2:1. Impreso

Esta noticia está contextualizada en el pasado, de manera que el único tiempo admisible en el subjuntivo de la oración subordinada, es el pluscuamperfecto: descartó que el despliegue hubiera sido, pues "el despliegue" es un hecho que ocurrió antes que se hicieran las declaraciones. Al utilizar el presente de subjuntivo se crea una ambigüedad, al dar la impresión de que el hecho aún no ha ocurrido o está por ocurrir.

e. "Dehecho, la caída de costos delasbotellas ya se empezó a sentir en el merca- 
do incluso antes de que rija el acuerdo."

El Comercio 5 ene. 2017 2:1. Impreso

La cláusula temporal "antes de que", solamente puede formalizarse con subjuntivo presente e imperfecto. En este ejemplo se rompe claramente la regla de concordancia: se empezó a sentir....antes de que rigiera..."

f. "Además, el temporal ocasionó derrumbes que taponaron la vía en el kilómetro 102. Largas filas de vehículos se formaron en ambos lados de la vía, a la espera de que se habilite la carretera para seguir el viaje." El Universo 7 ene.2017. 1:6

En esta oración subordinada se utiliza el presente de subjuntivo para referirse a una acción contextualizada en el pasado, lo cual afecta a la cadena de concordancia. Todos los verbos, excepto el subjuntivo, están en el pasado, y esto crea una ambigüedad, pues no queda claro si la carretera se habilitó o no.

9. "Édgar Jaramillo y Juan Carlos Solines, miembros de la instancia, acudieron ayer hasta la institución para que se les entregue la información "detallada" del concurso, pero recibieron el listado publicado en la página oficial." El Universo 7 ene.2017. 1:3
La acción de "entregar" se contextualiza en el pasado "ayer", por lo tanto la cláusula adverbial de finalidad debe formalizarse en imperfecto de subjuntivo: "acudieron ayer...para que se les entregara".

h. "Se mostró un extracto de una entrevista de Moreno en Telamazonas, en la cual opinó que Ecuador no dejaría el dólar mientras no se desarrolle la productividad; y se recogieron opiniones de los candidatos de oposición, criticándolo." El Universo 8 ene.2017. $1: 4$

En este párrafo escrito en estilo indirecto, contextualizado completamente en el pasado, la cláusula subordinada temporal se formaliza en presente de subjuntivo, con lo cual se altera la cadena de concordancia. Al decir "mientras no se desarrollara..."el sentido permanecería exactamente igual.

i. "Dos operaciones de inversión del 2015: una en marzo por $\$ 110$ mil y otra en octubre por $\$ 500$ mil, fueron la base para que el juez Nelson de la Cadena ordene la detención con fines investigativos del empresario quiteño Mauro T. vinculado a una supuesta defraudación tributaria." Ibid. 
La orden de detención es un hecho ocurrido en el pasado, razón por la cual esta cláusula subordinada de finalidad debería formalizarse en imperfecto de subjuntivo, con lo cual se ganaría precisión sintáctica y semántica.

j. "No podría recomendar que los maestros la vean en el aula con sus estudiantes porque Rita tiene una vida sexual abierta, que la serie muestra sin ambages..."Ibid. 1:6

De acuerdo con las reglas de concordancia gramatical, el imperfecto de subjuntivo es el tiempo que complementa una oración subordinante en tiempo pospretérito

k. "Haga lo que haga, el sujeto perdía, y su "salida" era la psicosis." Ibid.
Esta estructura reduplicativa en presente de subjuntivo, se refiere a un tiempo presente, que complementa a una oración referida en el pasado. De esta manera se afecta tanto la concordancia de tiempos, cuanto el sentido del mensaje. Lo indicado en este caso es: "Hiciera lo que hiciera, el sujeto perdía..."

A manera de observación general sobre la discordancia temporal en los casos analizados, se puede afirmar que esta produce una fuerte ambigüedad a la hora de establecer si las acciones expresadas en subjuntivo ocurrieron, o si están por ocurrir. Este hecho en teoría, debería preocupar inclusive a quienes sostienen que la lengua debe estar a disposición del usuario y que este, a su vez, puede imprimirle su sello personal o nacional en el momento de escribir un artículo de prensa.

\section{CONCLUSIONES}

Luego de haber analizado la utilización del imperfecto de subjuntivo en algunos casos tomados de los diarios "El Comercio" y "El Universo", se observa que existe inconsistencia en la concordancia temporal entre indicativo y subjuntivo.

Mientras se observan varios casos, especialmente en las páginas de opinión, en los que se aplica la norma de concordancia, sobre todo en la formulación de hipótesis, existen otros casos, de construcciones de doble acceso, en los que se puede utilizar el presente o el imperfecto de subjuntivo y en la mayoría de ellos se opta por el presente quizás, siguiendo la lógica del hablante cuando refiere acontecimientos que todavía no han ocurrido, es decir cuando el anclaje 
temporal es de posterioridad en relación con el verbo de la cláusula principal o se mencionan circunstancias de duración ilimitada o realización en un tiempo indeterminado.

Así mismo, este análisis ha comprobado que la utilización del imperfecto de subjuntivo con valor de indicativo, es muy frecuente. Este rasgo es, al parecer, característico de la redacción periodística a nivel internacional, y probablemente tenga una razón pragmática, pues el narrador opta por este modo de la no declaración, para no comprometerse completamente con lo que dice, sea por falta de seguridad o para salvar responsabilidades, o simplemente, porque el sonido del imperfecto de subjuntivo les parezca, quizás, más elegante o formal, pues se lo encuentra inclusive en partes mortuorios.

Luego de haber revisado los casos en los que se aplican las reglas canónigas y aquellos que son considerados parte del repertorio estilístico del periodismo, se han analizado los casos en los se produce una ruptura del consecutio temporum, y se ha encontrado que existe una notable tendencia a reproducir las características del habla quiteña y andina mencionadas al inicio de este trabajo. Es común hallar noticias de eventos pasados, que comienzan con un pretérito en la oración principal y que continúan con una oración subordinada en presente aun cuando esta se refiere a hechos ocurridos simultáneamente al momento del habla, especialmente en oraciones sustantivas que expresan intencionalidad o en oraciones adverbiales de finalidad y temporalidad.

Otra forma muy frecuente de discordancia se relaciona con la escritura en estilo indirecto; el verbo principal en pretérito, se combina con un futuro y se sigue con el presente de subjuntivo. La forma usual del imperfecto encontrada en los textos analizados es la terminada en -ra.

Es sabido que los diarios tienen correctores de estilo y se sabe también, que en ocasiones, su trabajo se ve limitado por la actitud de los autores de los artículos, que defienden su autonomía y derecho a escribir de acuerdo con su estilo particular; sin embargo, no se puede soslayar el hecho que la escritura periodística se inscribe dentro del ámbito del habla culta, cuyas características se han descrito en este artículo.

Al reiterar nuevamente que el afán de este trabajo ha sido describir un fenómeno lingüístico, sin otra motivación que no haya sido el meramente académico, se espera haber aportado para que aquellas personas que comparten este interés, continúen con sus reflexiones y estudios en este campo. 


\section{BIBLIOGRAFÎA}

Alarcos Llorach, E. (2000). Gramática de la lengua española. Madrid: Espasa Libros,

Butt, J. \& Benjamin, C. (2004). A new reference grammar of modern Spanish. London: Hooder Education, 2004.

Carrasco Gutiérez, Á. (1999) "El tiempo verbal y la sintaxis oracional. La consecutio temporum." Gramática descriptiva de la lengua española. Las construcciones sintácticas fundamentales. Relaciones temporales, aspectuales y modales. (Bosque, Ignacio y Demonte, Violeta Ed.) Madrid: Espasa Libros.

Estrella, A. (2000). El uso del verbo en el habla de Quito. Quito: Editorial Abya-Ayala.

Fernández, J, Fuente Rafael \& Siles, José. (1986).Curso intensivo de español. Gramática. Madrid: Sociedad general española de librería,

Fernández López, J. "La concordancia temporal en español Correspondencia de tiempos. Consecutio temporum." Hispanoteca. 2007. 2/08/2016 www.hispanoteca.eu.

Garcés D., F. (1982) "La substitución del pasado por el presente del subjuntivo en Quito." Tesis. Quito: Pontificia Universidad Católica del Ecuador.
Kany, C. (1969). Sintaxis Hispanoamericana. Madrid: Editorial Gredos.

Mancera Rueda, A. "La teoría de los géneros periodísticos en España: notas sobre su origen y estado de la cuestión." Web para profesionales de la comunicación iberoamericanos. 2009. Sala de Prensa. 15/07/2016 www.saladeprensa. org.

Miño-Garcés, F. (2006). Gazapos quiteños y cómo evitarlos. Quito: Centro de Publicaciones de la PUCE. Moreno de Alba, José (2001). El español de América. México: Fondo de cultura económica.

Pitloun, P. "El uso del imperfecto de subjuntivo en el habla culta costarricense." Revista de filología española (2006): 7.

Quilis, A./Esgueva, M./Gutiérrez, M. L./ Ruiz-Va, P. K.(1994).Lengua española. Curso de acceso. Madrid: Centro de estudios Ramón Areces,

Real Academia Española (2009). Nueva gramática de la lengua española. Morfología y sintaxis I. Madrid: Espasa libros.

Rojo, G. y Veiga, A. (1999). "El tiempo verbal. Los tiempos simples." Gramática descriptiva de la lengua 
española. Las construcciones sintácticas fundamentales. Relaciones temporales, aspectuales y modales. (Bosque, Ignacio y Demonte, Violeta Ed.) Madrid: Espasa libros.

Torrejón, A. (1993). Andrés Bello y la lengua culta. La estandarización del castellano en América en el siglo XXI. Boulder: Society of Spanish and Spanish-American Studies.

Verdú, V. "La lenta agonía del subjuntivo." Diario El País. 2003. Proz Forum
Spanish. 26/07/2016. http:// www.proz.com/forum/spanish/8591-la_lenta_agonia_del_ modo_subjuntivo_vicente_verd\%FA.html

Fuentes documentales

Diario "El Comercio". Quito: Grupo El Comercio. 2016, 2017.

Diario "El Universo". Guayaquil, Ecuador. 2017. 